\title{
A different look at measurement and interpretation of drug-induced stereotyped behavior
}

\author{
HENRY SZECHTMAN and DAVID EILAM \\ McMaster University, Hamilton, Ontario, Canada \\ PHILIP TEITELBAUM \\ University of Florida, Gainesville, Florida \\ and \\ ILAN GOLANI \\ Tel-Aviv University, Ramat Aviv, Israel
}

\begin{abstract}
Stereotyped behavior is a term used widely to describe behavior induced by psychostimulant drugs. However, a historical examination of what is meant by this term shows that different researchers use it to label different behavioral manifestations of the drug-induced syndrome. Moreover, the drug-induced syndrome has not been described adequately. We suggest that to do so requires a morphogenetic approach that will reveal the structure of the behavior as it unfolds during the course of the drug's action. This can be accomplished by decomposing the observed motor activity into independent kinematic variables. Using this approach, we have identified three kinematic variables (snout contact, progression, and turning) whose coupling explains much of the structure of behavior under apomorphine. Moreover, these variables can help us to understand the topography of drug-induced behavior in different environments and enhance the use of behavior to measure drug action.
\end{abstract}

When animals are injected with a psychoactive drug such as amphetamine or apomorphine, their behavior changes dramatically. The altered behavior is generally called stereotyped behavior. In the present examination of drug-induced stereotyped behavior, we consider what is an appropriate description of this behavior. We make two points: (1) Stereotyped behavior, as the term is used today in psychopharmacology research, does not possess a single meaning. Rather, different researchers use it to label different conspicuous features of the behavioral syndrome induced by amphetamine or apomorphine. (2) The behavioral syndrome induced by these drugs is best described morphogenetically. A morphogenetic description reveals not only how the many and varied behavioral symptoms result from the interaction of several relatively

We thank Evelyn Satinoff and Barbara Szechtman for comments on an earlier draft of the manuscript. The authors' research is supported by funds from the Medical Research Council of Canada (H. Szechtman and D. Eilam), Natural Sciences and Engineering Research Council (H. Szechtman), Whitehall Foundation (P. Teitelbaum), and Israeli Institute for Psychobiology-Charles E. Smith Family Foundation (Grant 6-87-8 to I. Golani). H. Szechtman is a Research Associate of the Ontario Mental Health Foundation. D. Eilam is presently a Postdoctorate Fellow in the Department of Neurosciences at McMaster University. P. Teitelbaum is in the Department of Psychology at the University of Florida, and I. Golani is in the Department of Zoology at Tel-Aviv University. H. Szechtman's mailing address is Department of Neurosciences, McMaster University, 1200 Main St. W., Hamilton, Ontario L8N 325, Canada. independent kinematic variables, but also how to construct meaningful behavioral categories for scoring the syndrome.

To show the various meanings of stereotyped behavior, we trace the appearance of this term in three literatures: the literature on screening for neuroleptic-like drugs, the literature on animal models of psychosis, and the literature on behavioral measures of dopaminergic activity. By examining what is measured, the review makes apparent that each literature records a different conspicuous feature of the drug-induced behavior. One measures what the animal does; another, how it does it; and the third, some combination of the above. Originally, each literature had a unique name for what it measured. With time, however, as the historical perspective reveals, all converged on one term, stereotyped behavior (Figure 1). In other words, what was measured did not change; only the name for it changed. We finish this part of the review by showing that apparent conflicts disappear when it is realized that although different aspects of drug-induced behavior are being measured, all are labeled stereotyped behavior.

To show the usefulness of a morphogenetic description of drug-induced behavior, we first point out that, unlike traditional analyses, which begin with a list of predefined behavioral acts, a morphogenetic analysis examines behavior as a spatiotemporal process. The goal of such analysis is to identify relevant kinematic variables that will reveal how behavior unfolds in time and will support or 


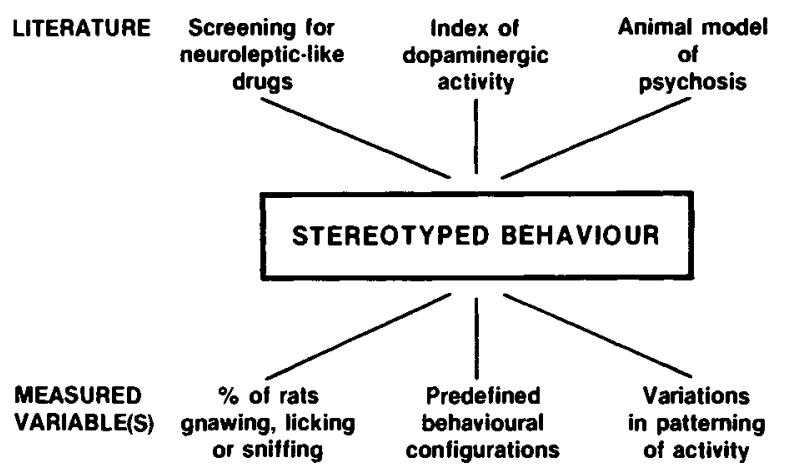

Figure 1. The different dependent variables that are labeled "stereotyped behavior" in different literatures.

refute the validity of the intuitively established acts defined by others. We then present a method to pursue such an analysis and illustrate the approach using our work on behavior of rats injected with apomorphine. Finally, after enumerating the usefulness of identifying relatively independent kinematic variables, we summarize our conclusions.

\section{Literature on Screening for Neuroleptic-Like Drugs: Chewing, Licking, Sniffing}

One conspicuous feature of the behavior of animals injected with apomorphine or amphetamine is chewing. Drug-treated rats pick up and chew wood shavings that cover the bottom of their cage. Such "chewing movements" are observed in almost all of the animals at 5 , 10 , and $20 \mathrm{~min}$ after an injection of $1.25 \mathrm{mg} / \mathrm{kg}$ of apomorphine (i.v.) and at 55 and $65 \mathrm{~min}$ after an injection of $10 \mathrm{mg} / \mathrm{kg}$ of amphetamine (i.v.) (Janssen, Niemegeers, \& Jageneau, 1960; Janssen, Niemegeers, Schellekens, \& Lenaerts, 1963). Because empirical evidence indicated that typical neuroleptic drugs of the haloperidol or chlorpromazine type blocked these responses, the antagonism of apomorphine- and amphetamine-induced chewing movements became, in the $1960 \mathrm{~s}$, one of the tests employed in screening for novel neuroleptic compounds.

In subsequent years, the criteria for scoring "chewing movements" expanded to include "gnawing, licking, or sniffing." This response category was initially labeled "stereotyped movements of the mouth and the tongue" (Janssen et al., 1963) but was later renamed "stereotyped behaviour' (Niemegeers, Lenaerts, Artois, \& Janssen, 1977). Correspondingly, the score that summarizes the presence or absence of these responses changed its name from "chewing score" (Janssen et al., 1963) to "stereotypy score" (Niemegeers et al., 1977). This stereotypy score was obtained independently of an "agitation score" that was measured concurrently and indicated the presence or absence of such responses as "ambulation, rearing, and jumping"' (Janssen et al., 1963). In the literature on screening for novel neuroleptic compounds, therefore, stereotyped behavior indicates the presence or absence of chewing, gnawing, licking, or sniffing (Figure 1).

\section{Literature on Animal Models of Psychosis: Repetitiveness}

Another striking feature of the behavior of animals treated with amphetamine or apomorphine is the altered patterning of activity. Drug-treated animals do not show the normal switching between different kinds of spontaneous activity. Instead, they often perform one kind of behavior over and over again, with little variation. As a label for this form of activity, Randrup and Munkvad (1967) suggested the word "stereotype."

In the same paper, Randrup and Munkvad pointed out that such repetitive activity also characterizes the behavior of humans with amphetamine psychosis. For example, the authors (Randrup \& Munkvad, 1967, p. 307) cited a 1966 study by Rylander, who noted that many patients showed "compulsive or automatic continuation for hours of one aimless activity, such as sorting objects in a handbag, manipulating the interiors of a watch, polishing fingernails to a point that sores [were] produced, etc.' 'Similar observations were made by Ellinwood (1967). The similarity in the form of activity of humans and animals under amphetamine suggested that studies of "stereotyped behavior"' in animals might provide insights into amphetamine-induced and endogenous psychoses in humans (Ellinwood, 1967; Randrup \& Munkvad, 1967), a notion that was formalized in the amphetamine model of psychosis (Snyder, Banerjee, Yamamura, \& Greenberg, 1974). Thus, in the literature on animal models of psychosis, stereotyped behavior refers to spontaneous activity performed repetitively with little variation.

Stereotyped behavior, as defined above, has often been measured by observers rating the sameness of activity over time (Rotrosen, Wallach, Angrist, \& Gershon, 1972). It has also been measured by assessing the randomness of patterns of behavior, as calculated from the sequence of "hole-dips" (a "hole-dip" is recorded automatically whenever a rat pokes its snout into one of the holes arranged on the floor of a maze; Makanjuola, Hill, Maben, Dow, \& Ashcroft, 1977). In still another method, stereotyped behavior has been evaluated by examining the sameness of routes that an animal took as it walked in an open field (Schiørring, 1979).

\section{Literature on Behavioral Measures of Dopaminergic Activity: Behavioral Configurations}

Still other features of the behavior of animals injected with apomorphine or amphetamine have been observed; these have been described in yet another literature and again called stereotyped behavior.

In 1967, Ernst proposed that apomorphine might be a direct agonist of dopamine receptors. His proposal was based on the following observations: (1) Apomorphine and dopamine are structurally similar; (2) apomorphine, 
amphetamine, and L-dopa (the precursor of dopamine), all induce the "gnaw compulsion" "syndrome in rats; and (3) after the depletion of catecholamines, amphetamine does not induce the "gnaw compulsion"' syndrome, but apomorphine does. Ernst suggested, therefore, that amphetamine acts indirectly on dopamine to induce the "gnaw compulsion" syndrome while apomorphine acts on the receptors themselves. In his experiments, Ernst used the following symbols to rate the "gnaw compulsion" syndrome (Ernst, 1967, p. 317):

-Rats showing no gnawing movements

+ Rats walking around in the cage, sniffing over the grid, occasionally licking the wires and putting the nose into the grid

++ Rats moving around, occasionally biting and gnawing at the wires

+++ Rats restricting their locomotion to a small area, and gnawing intensely on the bottom

++++ Rats remaining on the same spot for 5-10 minutes or longer, while jerkingly gnawing and clinging their teeth around the wires convulsively for longer periods, sometimes interrupted by short intermissions

Using very similar criteria, several investigators subsequently showed that by substituting scores of 0 to 4 for Ernst's symbols, one can obtain a linear relationship between the dose of apomorphine and the maximum rating of behavior (Costall \& Naylor, 1973) or between the log dose of apomorphine and the sum of all the ratings (taken every $10 \mathrm{~min}$ during a 1-h interval; McKenzie, 1972). Although Ernst used the behavioral syndrome merely to deduce that apomorphine stimulated dopamine receptors, subsequent investigators took the presence of the doseresponse relationship to indicate that this syndrome reflected activity in dopaminergic systems and that the behavioral score measured the intensity of dopaminergic activation. In other words, the syndrome is a behavioral assay of dopaminergic activity. The name of the syndrome was subsequently changed from "gnaw compulsion" 1 to "stereotyped behavior" and the score to a "stereotypy" score (Costall \& Naylor, 1973; McKenzie, 1972). Consequently, in the literature in which behavior is used to assay dopaminergic activity, stereotyped behavior specifies predefined complex behavioral configurations that follow each other in an orderly sequence.
It should be noted that the predefined behavioral configurations consist of an aggregate of several behavioral processes. These include the amount (uninterrupted duration) of: (1) locomotion or exploration; (2) sniffing; and (3) biting, gnawing, or licking. This can be seen clearly by slightly rearranging the description of the criteria used to rate stereotypy (see Table 1).

\section{Apparent Conflicts: Different \\ Aspects Measured}

Perhaps it is not surprising that once it became evident that the behavioral measures of each literature depend on activation of dopaminergic systems, they all adopted a single name (stereotyped behavior) for their dependent variables (see Figure 1). However, problems may arise if one applies the conclusions of one literature regarding stereotyped behavior to another without realizing that there are differences in what is measured and therefore in the meaning of "stereotyped behavior." Consider the following two examples.

1. It is often stated that moderate doses of amphetamine induce marked hyperactivity without discernible stereotyped behavior. Since, at those doses, amphetamine does not induce licking or gnawing, this conclusion follows from the definition and measurement of stereotyped behavior as used in the literature on screening for neuroleptic compounds. However, if the paths of locomotion exhibited by an amphetamine-treated rat are examined, one notes that, in an open field, the animal walks repeatedly along the same fixed route (Schiorring, 1979). According to Randrup and Munkvad's (1967) definition, the rat's activity is therefore "stereotyped," a conclusion at variance with the initial statement in this paragraph. Of course, the disagreement here is not real but semantic, inasmuch as the same term is used to label (and measure) different features of the drug-induced syndrome. In rating scales, stereotypy is partially defined in terms of presence or absence of locomotion; see Table 1. For quantitation, this definition precludes the existence of stereotypy independent of locomotion.

2. The behavioral configurations defined as stereotyped behavior in rating scales appear to be based on the assumption that changes in (a) locomotion, (b) sniffing, and (c) biting, gnawing, or licking depend on each other. For instance, the scale presumes that "exploratory activity" diminishes as "sniffing" becomes continuous (ratings 1-2) and that as "exploratory activity" disappears

Table 1

Scoring System Used for Estimation of the Intensity of Stereotypy

\begin{tabular}{cc}
\hline Score & Description of Stereotyped Behavior \\
\hline 0 & The appearance of the animals is the same as that of saline-treated rats \\
1 & Constant exploratory activity; discontinuous sniffing \\
2 & Periodic exploratory activity; $\quad$ continuous sniffing \\
3 & Very periodic exploratory activity; continuous sniffing; discontinuous biting, gnawing, or licking \\
4 & No exploratory activity;
\end{tabular}

Note-Rearrangement of table used by Costall and Naylor (1973). 
so does "sniffing" while "biting, gnawing, or licking" appear and become continuous (rating 4; see Table 1). In fact, however, when tested in slightly different environments, drug-injected rats may exhibit behavioral configurations at variance with the above criteria or behaviors that are not even taken into consideration by those criteria. For example, some time after being injected with apomorphine, a rat tested in a large open field may exhibit continuous sniffing, but no biting or licking and no exploratory activity, since it remains in one place in the open field (Figure 2, bottom path for each animal). In a different environment, a small, smooth Plexiglas enclosure, the animal may show a response that is rarely observed in a wire-mesh cage, namely, continuous and

\section{SHRINKAGE OF EXPLORATORY SPACE}

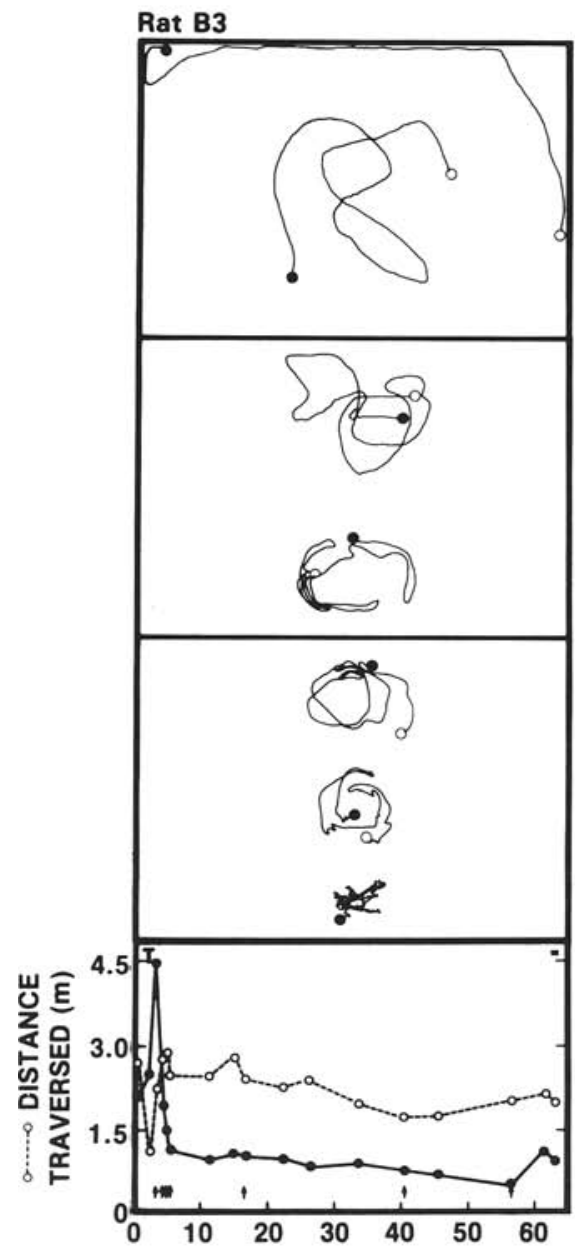

Rat A1

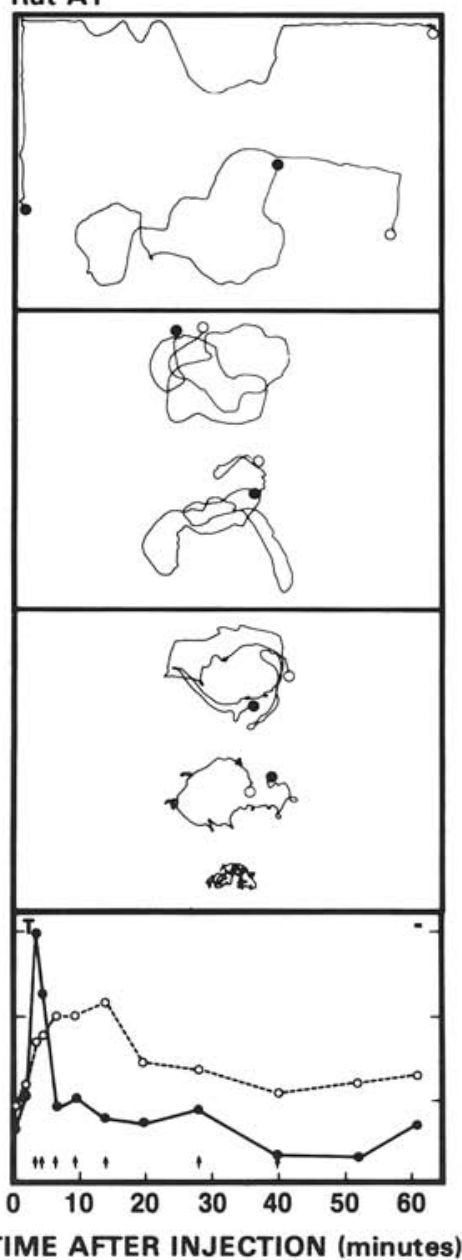

Rat A2

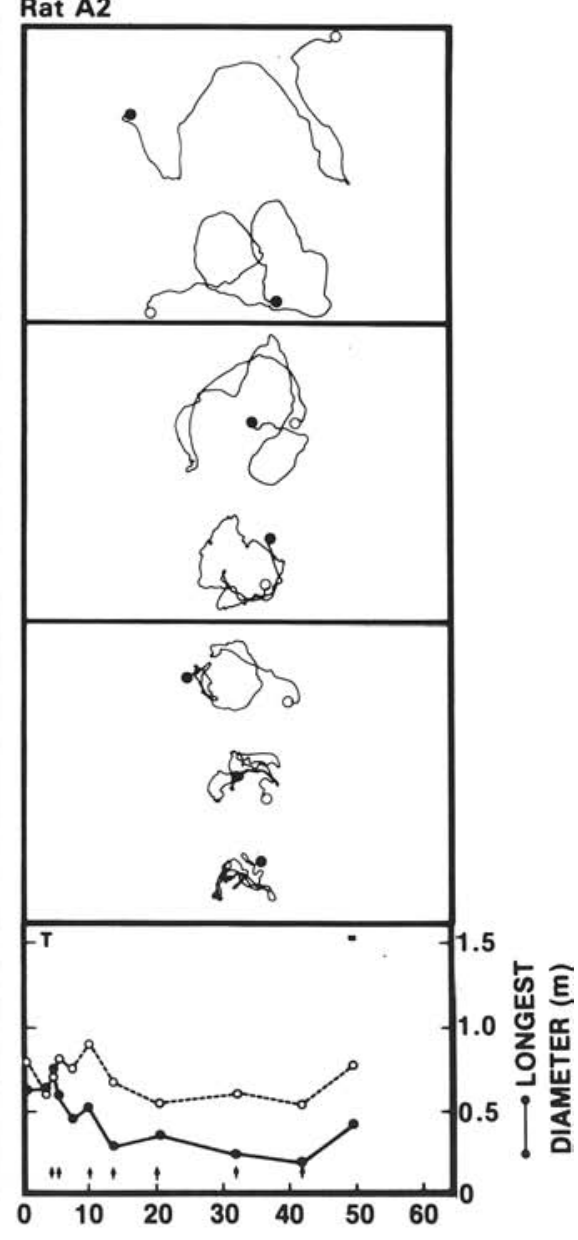

Figure 2. Seven representative paths traced by the snout of each of 3 rats exploring the open field in successive 15-sec intervals during the course of apomorphine's action. Snout trajectories were drawn from film records. Rectangles are a scale of the open field and every trajectory is drawn proportionately (two separate trajectories are shown in the top rectangle, two in the middle one, and three in the bottom one). The beginning of the path is indicated by an open circle $(0)$ and the end by a closed circle (๑). For the parposes of this illustration, the trajectories were positioned along the vertical midline of the open field, regardless of their actual physical location in the open field. Each of the seven arrows near the baseline on the graph for each animal indicates the time during the course of drug action at which such a trajectory was exhibited. The seven trajectories from top to bottom correspond to the seven arrows on each graph, from the beginning of the drug's action to its end. The length of each path (distance traversed) was measured from tracings using an image analyzer. The largest diameter of the path was determined by fitting the longest possible line between two extreme edges of the path. Whereas distance traversed measures path length, longest diameter is an indication of the range of the environment explored by the rat. Thus, the same path length may densely cover a limited area, reflecting its detailed repetitive examination (bottom samples) or merely encircle a larger one (top samples), suggesting a one-time examination of ever-new locations. The graph indicates that while the path length (distance traversed) diminishes only slightly during the course of action of apomorphine, the range covered by the rat's snout (longest diameter) becomes progressively smaller and more condensed until it ultimately densely covers an area, the dimension of which is smaller than the rat's body length. (From "The Morphogenesis of Stereotyped Behavior Induced by the Dopamine Receptor Agonist Apomorphine in the Laboratory Rat" by H. Szechtman, P. Teitelbaum, K. Ornstein, and I. Golani, 1985, Neuroscience, 14, p. 794. Copyright 1985 Pergamon Press. Adapted by permission.) 
repetitive rearing against the cage wall (Szechtman, Ornstein, Teitelbaum, \& Golani, 1982). Even though the above examples do not fit the criteria of stereotyped behavior as defined by the rating scales, the behavior can be labeled "stereotyped" if one of the other definitions is used, since it is repetitive and does involve sniffing.

Thus, an apparent disagreement may be a mere consequence of the different definitions of stereotyped behavior. But the problem extends beyond a definition of stereotyped behavior. When observing animals injected with amphetamine or apomorphine, one becomes convinced that the various behavioral measures, singly or together, fail to capture how the actual behavior unfolds in time. In the next section, we suggest that to do this requires a morphogenetic approach.

\section{Morphogenesis of Behavior and Kinematic Variables}

Traditional analyses of drug-induced behavior start off with a ready list of arbitrarily defined behavioral acts (such as sniffing, head down, nose-poking, or rearing). The objective of those analyses is to discover the frequency, duration, and sequence of the acts during the course of the drug's action (e.g., Ellinwood \& Balster, 1974; Fray, Sahakian, Robbins, Koob, \& Iversen, 1980; Ljungberg \& Ungerstedt, 1978; Norton, 1973). But such analyses cannot convey the morphogenesis of behavior, that is, the structure of behavior as it unfolds in time. Because behavior is a spatiotemporal process, it must be examined as such (Golani, 1976, 1981). By having predefined categories at the outset of analysis, one already presumes that the ongoing behavioral process is composed of these particular separate acts. In a morphogenetic analysis, instead, there are no a priori acts. Rather, one seeks the relevant continuous variables that, through their interaction, reveal and explain the structure of behavior during the course of the drug's action and support or refute acts defined in other studies. Below, we consider a method that is suitable for this purpose. We then present an example of the morphogenetic approach using our analysis of the behavior of rats treated with apomorphine (Szechtman, Ornstein, Hofstein, Teitelbaum, \& Golani, 1980; Szechtman, Teitelbaum, Ornstein, \& Golani, 1985).

To be considered relevant, a variable should fulfill the following four criteria: (1) It should measure an aspect of the actual body movements performed by the animal, (2) it should show a systematic change over time, (3) it should be relatively independent of other measured variables, and (4) the coupling among the isolated variables should reconstitute the observed behavioral patterns. These criteria, respectively, (1) avoid the arbitrary division of ongoing motor activity into acts, (2) suggest an orderly and (3) unique process, and finally (4) use synthesis as a check for the correctness of analysis.

A suitable technique to describe movement in time is the Eshkol-Wachmann Movement Notation (Eshkol, 1980; Eshkol \& Wachmann, 1958). This notation system is a structured language specifically devised to record and analyze body movements. It has been used to describe classical ballet (Eshkol, 1968), physiotherapeutics (Eshkol, 1969, 1971, 1980), social interaction in mammals (Golani, 1976; Yaniv \& Golani, 1987), recovery of movement following lateral hypothalamic lesions in rats (Golani, Wolgin, \& Teitelbaum, 1979), drug-induced behavior in laboratory (Pellis, Pellis, Cheshire, Roland, \& Teitelbaum, 1987; Szechtman et al., 1980; Szechtman et al., 1985; Teitelbaum, Pellis, \& DeVietti, in press) and wild (Eilam, 1988) rats, the ontogeny of exploration (Golani, Bronchti, Moualem, \& Teitelbaum, 1981; Eilam \& Golani, in press) and grooming (Golani \& Fentress, 1985 ) in infant rats and mice, the development of play behavior (Pellis, 1981, 1983) and courtship (Pellis, 1982) in birds, and predatory behavior in various mammalian carnivores (Pellis \& Officer, 1987; Pellis et al., in press). One particular advantage of this method is that it allows continuous measurement of several kinematic (movement) variables in parallel.

Using this approach in our analysis of behavior under apomorphine (Szechtman et al., 1980; Szechtman, 1985), and guided by previous work on recovery of movement after damage to the lateral hypothalamus (Golani et al., 1979), we have identified three relevant variables (snout contact, progression, and turning). The coupling among these variables reveals much of the structure of behavior during the course of action of apomorphine. Moreover, it explains the sequence of appearance of several of the seemingly unrelated behavioral acts observed after an injection of the drug. We first present the profile of each variable separately, and then consider how coupling among them reconstitutes much of the observed behavior.

Figure 3 shows that each of these variables has a unique time of peak action, amplitude, and rate of change. Snout contact (i.e., tactile contact between the snout and an environmental surface) is established first, at 1.5-3 min after a subcutaneous injection of $1.25 \mathrm{mg} / \mathrm{kg}$ of apomorphine. It is maintained, without interruptions, until the drug begins to lose its activating effects, about 50-70 min later. (Dose response data for i.p. injections are provided in Szechtman et al., 1982). Forward steps, which are a measure of the distance that the body is displaced (progresses), appear next and reach their peak amplitude rather quickly, at about $5 \mathrm{~min}$ after injection (range: 2.5-6.5 min). Usually, the amount of forward progression then declines rapidly to almost zero by $10 \mathrm{~min}$ after injection. Last to appear is turning, as measured by the change in horizontal angular orientation of the head. Turning is nearly absent when snout contact is established, then rises slowly, reaching its peak amplitude about $15 \mathrm{~min}$ after injection (range: $8.5-26.5 \mathrm{~min}$ ). It remains near this level or declines very slowly during the rest of the time that the drug is active (i.e., until snout contact is broken and grooming appears).

Using the above three kinematic variables, it can be shown, to a first approximation, that the behavior observed in the open field at any one time after injection is directly related to the values of these variables at that 


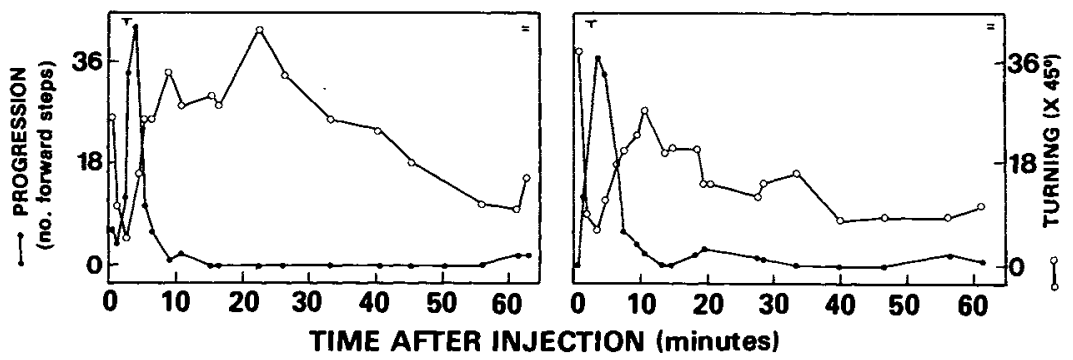

Figure 3. Time course of progression $(\bullet)$ and turning $(0)$ in 2 representative rats injected with $1.25 \mathrm{mg} / \mathrm{kg}$ of apomorphine and placed in a large open field (a glass table $100 \times 140$ $\times 150 \mathrm{~cm}$ high, without any walls). Amount of progression is measured in units of forward steps; amount of turning is measured in units of $\mathbf{4 5}^{\circ}$. Each data point represents $15 \mathrm{sec}$ of the animal's activity. Measurements were taken from film records of the rat's behavior. The position of the label $T$ indicates the time at which uninterrupted snout contact with the table surface was established; the position of the label = indicates the time at which snout contact was released. Note that once snout contact is established, there is a rapid rise in the amount of forward progression: it peaks at approximately $5 \mathrm{~min}$ after injection of the drug. As the amount of forward progression declines, the amount of turning increases, reaching a peak 10-20 min after drug injection. The amount of turning then declines slowly over the remainder of the hour. (From "The Morphogenesis of Stereotyped Behavior Induced by the Dopamine Receptor Agonist Apomorphine in the Laboratory Rat" by H. Szechtman, P. Teitelhaum, K. Ornstein, and I. Golani, 1985, Neuroscience, 14, p. 787. Copyright 1985 Pergamon Press. Adapted by permission.)

time. At first, as snout contact is established and the amount of turning is small while the frequency of forward steps is large, the predominant behavior is forward locomotion with the snout close to the ground (Figure 4, top). Later, when the amount of turning is higher and the frequency of forward steps is smaller, the predominant response is circling (Figure 4, second row); that is, the rat turns while stepping forward (the direction of circling is not necessarily constant throughout). Later still, when the amount of turning is very high and the frequency of forward steps is low, the rat revolves in ever tighter circles (Figure 4, third row). Finally, when the amount of turning is near its peak and the frequency of forward steps is nil, the rat pivots in place (Figure 4, bottom) or merely moves the forequarters from side-to-side. Throughout these stages, the snout remains in contact with the table surface.

Thus, such seemingly unrelated acts as the sniffing, keeping head down, forward locomoting, circling, rotating, pivoting, and side-to-side head moving observed during the course of action of apomorphine appear to be the result of the simultaneous occurrence of three independent processes (snout contact, progression, and turning), each with a unique time of peak action, amplitude, and rate of change. In other words, a quantitative continuity results in the qualitative discontinuities.

As the above example from our work indicates, there are two compelling reasons why it is useful to analyze the behavioral syndromes induced by drugs in terms of relatively independent kinematic variables. First, it identifies how the structure of behavior develops in time. In so doing, it reveals the continuum from normal to abnormal activity. Second, it reveals how several complex and seemingly disparate behavioral acts are merely combina- tions of a few simple quantitative continua. These continuous variables probably relate more meaningfully to the corresponding underlying neurochemical systems that are activated by the drug than do behavioral " acts." But analysis in terms of independent kinematic variables also increases our understanding of some hitherto puzzling phenomena. In addition, it may enhance behavioral measures of drug action. These are discussed in the next section.

\section{Usefulness of Morphogenetic Analysis}

One hitherto puzzling phenomenon is the changing topography of drug-induced behavior in different environments. For instance: (1) in an open field without walls, an apomorphine- or amphetamine-injected rat does not rear (Mumford, Teixeira, \& Kumar, 1979; Szechtman et al., 1980), but in an enclosure with walls (Decsi, Gacs, Zambo, \& Nagy, 1979; Szechtman et al., 1982) it may do so continually (Figure 5, left); (2) on top of a cylinder, it exhibits "cliff-jumping" (Weismann, 1971); and (3) in a rotometer with one side of its head bandaged, it circles predominantly in one direction, away from the bandaged side (Szechtman, 1983). One way to interpret the lack of rearing is to postulate a drug-induced attenuation of "risktaking" in the unwalled environment (Mumford et al., 1979). However, our morphogenetic analysis suggests a more parsimonious explanation (Szechtman et al., 1982): the absence of rearing in an open field reflects the fact that rearing there would entail breaking snout contact. In a walled enclosure, being upright does not involve breaking snout contact as the rat elevates itself with its snout against the wall. In fact, the rearing or climbing response can be considered as forward progression which, because the physical environment provides a particular input to 


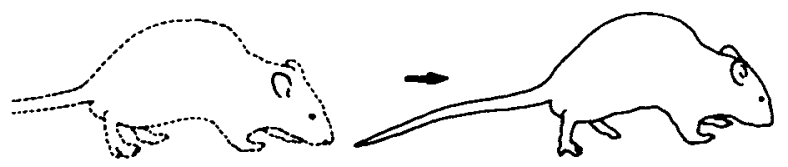

peripheral input that reaches the snout, yielding circling towards the side of greater input. Thus, all these seemingly qualitative variations in the topography of behavior can be easily understood in terms of a molding of the same variables (progression and turning) into different config-

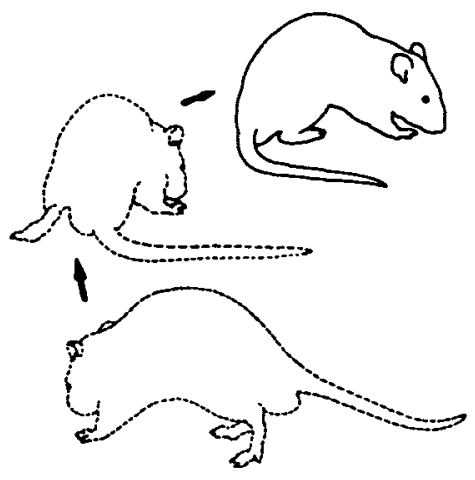
urations by different sensory input encountered during snout contact.

Another phenomenon not readily understood is how "sniffing" becomes transformed into "biting" at higher doses of apomorphine or amphetamine. Although our morphogenetic analysis does not reveal this transformation, we hypothesize that, because snout contact is a fundamental effect of apomorphine, the appearance of biting may be the result of the spread of allied reflexes. MacDonnell and Flynn (1966) have demonstrated that, in cats, electrical stimulation of the lateral hypothalamus can induce biting in response to previously ineffective tactile probing around the mouth; furthermore, the effective area for triggering the response becomes greater (spreads)

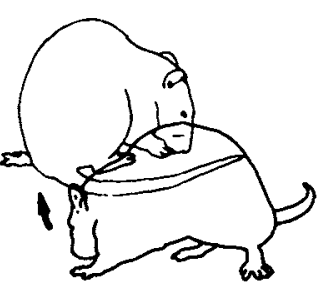
with increasing current intensity. Huston, Nef, Papadopoulos, and Welzl (1980) demonstrated a similar triggering of biting by tactile input in rats after an injection of apomorphine. These findings suggest that the mouthing exhibited by rats injected with apomorphine may be an instance of biting that is triggered or facilitated by tactile input encountered during snout contact. Indeed, the fact that surface irregularities potentiate the expression of gnawing is consistent with this suggestion (Lal \& Sourkes, 1973; Szechtman et al., 1985).

Finally, the decomposition of the behavioral syndrome induced by apomorphine into independent variables may also enhance its value for usage as a behavioral assay. For instance, the duration of drug action may be assessed simply by recording the duration of snout contact. Regardless of the topography of drug-induced behavior, be it sniffing, biting, licking, walking, climbing, circling, revolving, or pivoting, or of variations in the propensity to bite among different substrains of rats (Figure 5, right), the cessation of maintaining snout contact (as well as the appearance of grooming) invariably signals the end of the activating effects of apomorphine (Szechtman et al., 1982; see also Beck, Chow, \& Cooper, 1986; Molloy \& Waddington, 1987). With respect to rotational behavior, another commonly used behavioral assay (Ungerstedt \& Arbuthnott, 1970), it may prove useful to measure progression and turning independently rather than to confound these two variables by measuring merely the number of circles. Circling (which involves both forward progression and turning) and pivoting (which involves turning only) are performed using different stepping patterns (Golani et al., 1979; Szechtman et al., 1980, 1985; Teitelbaum et al., in press). Thus, by recording stepping patterns, it may be possible to measure drug effects on progression and on turning separately, even in a rotometer (Szechtman et al., 1985; Teitelbaum, Szechtman, Sirkin, \& Golani, 1982). Indeed, this procedure has already succeeded in revealing differences in the circling induced by 


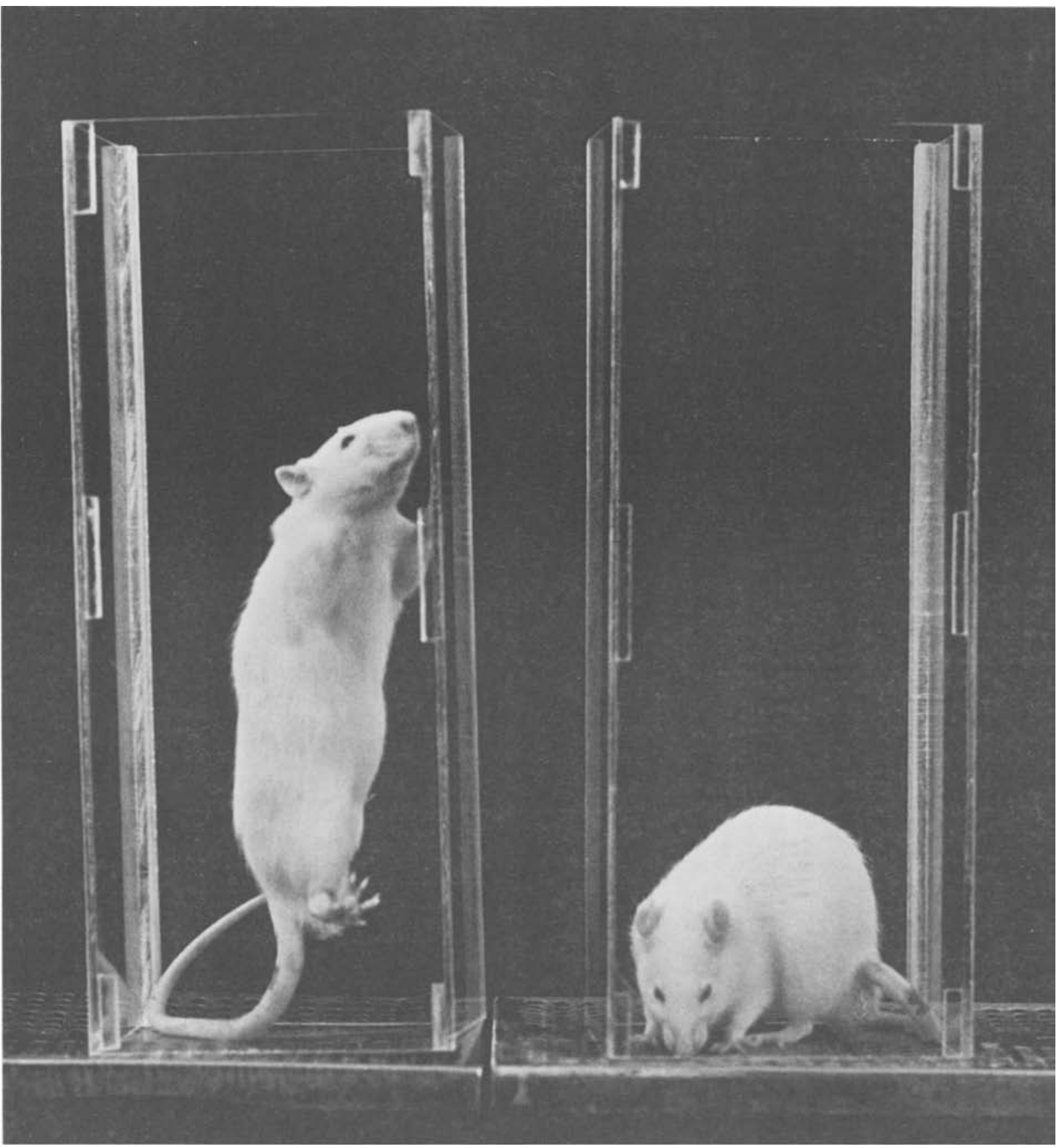

Figure 5. Climbing or gnawing in response to apomorphine. At the same dose of apomorphine, Wistar rats from one supplier (left) predominantly exhibit climbing, whereas those from another supplier (right) predominantly exhibit gnawing. (From "Snout Contact Fixation, Climbing and Gnawing During Apomorphine Stereotypy in Rats from Two Substrains" by H. Szechtman, K. Ornstein, P. Teitelbaum, and I. Golani, 1982, European Journal of Pharmacology, 80, p. 387. Copyright 1982 Elsevier Science Publishers. Adapted by permission.)

amphetamine and apomorphine in rats with unilateral lesions of the substantia nigra (Ziegler \& Szechtman, 1988).

\section{Summary}

Different investigators use the term "stereotyped behavior" to label different features of the behavioral syndrome induced by amphetamine or apomorphine. There- fore, it is not surprising that different investigators observing the same animal may reach conflicting conclusions regarding the presence of stereotyped behavior. Although many investigators have, indeed, indicated that stereotyped behavior is more complex than the dependent measures would suggest (e.g., Fray et al., 1980; Lyon \& Robbins, 1975), their analyses of the drug-induced syn- 
drome are conceptually very similar: they all begin with some a priori defined behavioral acts and then measure their frequency and/or duration during the course of the drug's action. Thus, in one study (Norton, 1973), 15 behavioral categories were recorded, while in others, 10 (Fray et al., 1980), 9 (Ellinwood \& Balster, 1974), and 8 (Ljungberg \& Ungerstedt, 1978) were measured. It is readily apparent that there is no theoretical rationale for choosing any particular acts to describe the drug-induced behavior, since each study uses different ones. Perhaps the term "stereotyped behavior" has lost its usefulness and what is required is a different approach to labeling the drug-induced syndrome. Behavior must be analyzed first. Once the relevant behavioral variables are identified, it is then possible to construct the categories that are meaningful for scoring the syndrome. We believe that our attempt to decompose the behavioral syndrome induced by apomorphine into relatively independent kinematic variables is a step in this direction; however, it is only a first step. Indeed, in order to provide meaningful correlations between brain mechanisms and behavior, the analysis of behavior will require as much sophistication and attention to detail as does the analysis of the brain.

\section{REFERENCES}

Amsler, C. (1923). Beitrage zur Pharmakologie des Gehims. NaunynSchmiedebergs Archiv fur Experimentelle Pathologie und Pharmakologie, 97, 1-14.

BeCK, C. Н. М., Chow, H. L., \& CoOper, S. J. (1986). Dose-related response of male rats to apomorphine-snout contact in the open-field. Physiology \& Behavior, 37, 819-825.

Costall, B., \& NAYlor, R. J. (1973). The role of telencephalic dopaminergic systems in the mediation of apomorphine-stereotyped behavior. European Journal of Pharmacology, 24, 8-24.

Decsi, L., Gacs, E., Zambo, K., \& NagY, J. (1979). Simple device to measure stereotyped rearing of the rat in an objective and quantitative way. Neuropharmacology, 18, 723-725.

EilAM, D. (1988). Exploratory behavior in Norway rats (Rattus norvegicus): Normal behavior and the behavior under the psychoactive drug amphetamine. Unpublished doctoral dissertation, Tel-Aviv University, Ramat Aviv, Israel.

Ellam, D., \& Golani, I. (in press). The ontogeny of exploratory behavior in the house rat (Rattus rattus): The immobility-mobility gradient. Developmental Psychobiology.

Ellinwood, E. H., JR. (1967). Amphetamine psychosis: 1. Description of the individuals and processes. Joumal of Nervous \& Mental Diseases, 44, 273-283.

ELIINwOOD, E. H., JR., BALSTER, R. L. (1974). Rating the behavioral effects of amphetamine. European Journal of Pharmacology, 28, $35-41$.

ERNST, A. M. (1967). Mode of action of apomorphine and dexamphetamine on gnawing compulsion in rats. Psychopharmacologia (Berlin), 10, 316-323.

EshKol, N. (1968). Classical ballet. Holon, Israel: Movement Notation Society.

Eshkol, N. (1969). Physical training. Holon, Israel: Movement Notation Society.

Eshkol, N. (1971). The hand book. Holon, Israel: Movement Notation Society.

EshKOL, N. (1980). 50 lessons by Dr. Moshe Feldenkrais. Holon, Israel: Movement Notation Society.

EshKoL, N., \& W ACHMANN, A. (1958). Movement notation. London: Weidenfeld \& Nicolson.

Fray, P. J., Sahakian, B. J., Robbins, T. W., KoOb, G. F., \& Iver-
SEN. S. D. (1980). An observational method for quantifying the behavioural effects of dopamine agonists: Contrasting effects of $d$ amphetamine and apomorphine. Psychopharmacology, 69, 253-259.

GolaNI, I. (1976). Homeostatic motor processes in mammalian interaction: A choreography of display. In P. P. G. Bateson \& P. H. Klopfer (Eds.), Perspectives in ethology (pp. 69-134). New York: Plenum Press.

GoLAN1, 1. (1981). The search for invariants in motor behavior. $\ln \mathrm{K}$. $1 \mathrm{~m}$ melmann, G. W. Barlow, L. Petrinovich, \& M. Main (Eds.), Behavioural development: The Bielefield Interdisciplinary Project (pp. 372-390). Boston: Cambridge University Press.

Golani, l., Bronchti, G., Moualem, D., \& Teitelbaum, P. (1981). "Warm-up" along dimensions of movement in the ontogeny of exploration in rats and other infant mammals. Proceedings of the $\mathrm{Na}$ tional Academy of Science, USA, 78, 7226-7229.

Golani, 1., \& Fentress, J. C. (1985). Early ontogeny of face grooming in mice. Developmental Psychobiology, 18, 529-544.

Golani, 1., Wolgin, D., \& Tertelbaum, P. (1979). A proposed natural geometry of recovery from akinesia in the lateral hypothalamic rat. Brain Research, 164, 237-267.

huston, J. P., Nef, B., Papadopoulos, G., \& Welzl, H. (1980). Activation and lateralization of sensorimotor field for perioral biting reflex by intranigral GABA agonist and by systemic apomorphine in the rat. Brain Research Bulletin, 5, 745-749.

Janssen, P. A. J., Niemegeers, C. J. E., Jageneau, A. H. M. (1960). Apomorphine antagonism in rats. Arzneimittel-Forschung, 10 , 1003-1005.

Janssen, P. A. J., Niemegeers, C. J. E., Schellekens, K. H. L., a Lenaerts, F. M. (1963). Is it possible to predict the clinical effects of neuroleptic drugs (major tranquilizers) from animal data? Part IV: An improved experimental design for measuring the inhibitory effects of neuroleptic drugs on amphetamine-induced "chewing" and "agitation" in rats. Arzneimittel-Forschung, 17, 841-854.

LAL, S., \& Sourkes, T. L. (1973). Ontogeny of stereotyped behavior induced by apomorphine and amphetamine in the rat. Archives Internationales de Pharmacodynamie et de Therapie, 202, 171-182.

LJUNGBERG, T., \& UNGERSTEDT, U. (1978). A new method for simultaneous registration of 8 behavioural parameters related to monoamine neurotransmission. Pharmacology, Biochemistry \& Behavior, 8, 483-489.

Lyon, M., \& Robins, T. W. (1975). The action of central nervous system stimulant drugs: A general theory concerning amphetamine effects. In W. Essman \& L. Valzelli (Eds.), Current developments in psychopharmacology (pp. 89-163). New York: Spectrum Press.

MacDonnell, M. F., \& FLYNN, J. P. (1966). Control of sensory fields by stimulation of hypothalamus. Science, 15, 1406-1408.

Makanjuola, R. O. A., Hill, G., Maben, 1., Dow, R. C., \& AschrofT, G. W. (1977). Automated method for studying exploratory and stereotyped behavior in rats. Psychopharmacology, 52, 271-277.

McKenzie, G. M. (1972). Role of the tuberculum olfactorium in stereotyped behaviour induced by apomorphine in the rat. Psychopharmacologia (Berlin), 23, 212-219.

Molloy, A. G., \& Waddington, J. L. (1987). Assessment of grooming and other behavioural responses to the D-1 dopamine receptor agonist SK \& F 38393 and its $R$ - and S-enantiomers in the intact adult rat. Psychopharmacology, 92, 164-168.

Mumford, L., Teixeira, A. R., Kumar, R. (1979). Sources of variation in locomotor activity and stereotypy in rats treated with $d$ amphetamine. Psychopharmacology, 62, 241-245.

Niemegeers, C. J. E., Lenaerts, F. M., Artois, K. S. K., \& JansSEN, P. A. J. (1977). Interaction of drugs with apomorphine, tryptamine and norepinephrine. A new 'in vivo' approach: The ATN-test in rats. Archives Intemationales de Pharmacodynamie et de Therapie, 227, 238-253.

NorTon, S. (1973). Amphetamine as a model for hyperactivity in rat. Physiology \& Behavior, 11, 181-186.

Pelus, S. M. (1981). A description of social play by the Australian magpie Gymnorhina tibicens based on Eshkol-Wachman notation. Bird Behaviour, 3, 61-79.

Pelus, S. M. (1982). An analysis of courtship and mating in Cape Barren 
goose Cereopsis novaehollandiae Latham based on Eshkol-Wachman movement notation. Bird Behaviour, 4, 30-41.

Peluis, S. M. (1983). Development of head and foot coordination in the Australian magpie Gymnorhina tibicens and the function of play. Bird Behaviour, 4, 57-62.

Peluis, S. M., O'Brien, D. P., Pellis, V. C., Teitelbaum, P., WolGIN, D. L., KENNEDY, S. (in press). Escalation of feline predation along a gradient from avoidance through "play" to killing. Behavioral Neuroscience.

Pelus, S. M., \& OfFicer, R. C. E. (1987). An analysis of some predatory behavior patterns in four species of carnivorous marsupials (Dasyuridae), with comparative notes on the eutherian cat Felis catus. Ethology, 75, 177-196.

Pellis, S. M., Pellis, V. C., Cheshire, R. M., Roland, N. F., \& Teitelbaum, P. (1987). Abnormal gait sequence in locomotion after atropine treatment of catecholamine deficient akinetic rats. Proceedings of the National Academy of Science, USA, 84, 8750-8753.

RANDRUP, A., \& MUNKVAD, I. (1967). Stereotyped activities produced by amphetamine in several animal species and man. Psychopharmacologia (Berlin), 11, 300-310.

Rotrosen, J., WAllach, M. B., Angrist, B., \& Gershon, S. (1972). Antagonism of apomorphine-induced stereotypy and emesis in dogs by thioridazine, haloperidol, and pimozide. Psychopharmacologia (Berlin), 26, 185-194.

SCHIGRRING, E. (1979). An open field study of stereotyped locomotor activity in amphetamine-treated rats. Psychopharmacology, 66, 281-287.

Snyder, S. H., Banerjee, S. P., Y amamura, H. I., \& Greenberg, D. (1974). Drugs, neurotransmitters, and schizophrenia. Science, 184, 1243-1253.

Steiner, H., Huston, J. P., \& Morgan, S. (1986). Apomorphine reverses direction of asymmetry in facial scanning after 10 days of unilateral vibrissae removal in rats: Vibrissotomy-induced denervation supersensitivity? Behavioral Brain Research, 22, 283-287.

SzeChtman, H. (1983). Peripheral sensory input directs apomorphineinduced circling in rats. Brain Research, 264, 332-335.

Szechtman, H., Ornstein, K., Hofstein, R., Teitelbaum, P., * GolANI, I. (1980). Apomorphine induces behavioral regression: A sequence that is the opposite of neurological recovery. In E. Usdin, T. L. Sourkes, \& M. B. H. Youdim (Eds.), Enzymes and neurotransmitters in mental disease (pp. 511-517). Chichester: Wiley.
Szechtman, H., Ornstein, K., Teitelbaum, P., \& Golani, I. (1982). Snout contact fixation, climbing and gnawing during apomorphine stereotypy in rats from two substrains. European Joumal of Pharmacology, 80, 385-392.

Szechtman, H., Tertelbaum, P., Ornstein, K., \& Golani, I. (1985). The morphogenesis of stereotyped behavior induced by the dopamine receptor agonist apomorphine in the laboratory rat. Neuroscience, 14, 783-798.

Teitelbaum, P., Pellis, S. M., \& DeVietti, T. L. (in press). Disintegration into stereotypy induced by drugs or brain damage: A microdescriptive behavioral analysis. In S. J. Cooper \& C. T. Dourish (Eds.), Neurobiology of behavioural stereotypy. Oxford: Oxford University Press.

Teitelbaum, P., Szechtman, H., Sirkin, D., Golani, I. (1982). Dimensions of movement, movement subsystems and local reflexes in the dopaminergic systems underlying exploratory locomotion. In M. Y. Spiegelstein \& A. Levy (Eds.), Behavioral models and the analysis of drug action (Pp. 357-385). Amsterdam: Elsevier Scientific Publishing.

UNGERSTEDT, U., \& ARBUTHNOTT, G. W. (1970). Quantitative recording of rotational behavior in rats after 6-hydroxy-dopamine lesions of the nigrostriatal dopamine system. Brain Research, 24, 485-493.

WeISMANN, A. (1971). Cliff jumping in rats after intravenous treatment with apomorphine. Psychopharmacologia (Berlin), 21, 60-65.

YaNIV, Y., \& Golani, I. (1987). Superiority and inferiority: A morphological analysis of free and stimulus bound behaviour in honey badger (Mellivora capensis) interactions. Ethology, 74, 89-116.

ZiegLer, M., \& SzechTMAN, H. (1988). Differences in the behavioral profile of circling under amphetamine and apomorphine in rats with unilateral lesions of the substantia nigra. Behavioral Neuroscience, 102, 276-288.

\section{NOTE}

1. Ernst seems to have translated the term "Zwangsnagen" used by Amsler (1923) as "gnaw compulsion." Another translation is "compulsory" gnawing (Janssen et al., 1963) or "forced" gnawing.

(Manuscript received April 10, 1987; revision accepted for publication February 18, 1988.) 